\title{
José Manuel Rojas González, ¿Para qué carretas sin marimbas? Hacia una historia crítica de la práctica de la música "clásica" en Costa Rica (1971-2011)
}

\section{Wanda C. Rodríguez Arocho ${ }^{1}$}

Recepción: 3 de marzo de 2016 / Aprobación: 30 de marzo de 2016

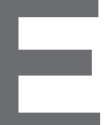

I prólogo que escribió el Dr. Camilo Retana, profesor de Filosofía, al texto de José Manuel Rojas González captura magistralmente los tres principales logros del trabajo. Primero, su aporte como fuente de información nueva o, al menos, desconocida para el público general con respecto a la música en Costa Rica. Segundo, su reclamo para reenfocar nuestra mirada a esa música, es decir, para mirar las cosas que habíamos visto antes de una manera diferente (me atrevo a sugerir que toda persona que lea este libro experimentará de manera diferente el próximo concierto al que asista). Tercero, su potencial como herramienta cultural para promover discusiones y debates, para avanzar la indagación dialógica y la problematización como prácticas para transformar la conciencia y para abrir camino a nuevos frentes de reflexión-acción en torno a las producciones culturales en su complejidad. Este potencial parece estar realizándose, si consideramos el interés que el libro ha despertado en algunos medios de comunicación masiva en Costa Rica.

Para alcanzar estos logros mencionados Rojas hace despliegue de su formación y su experiencia en el oficio de la música, su dominio en el campo de los Estudios Culturales de profunda raigambre crítica y de sus experiencias de vida. Este trabajo es una síntesis de pensamiento reflexivo y crítico, sensibilidad y afectividad, conciencia social y compromiso ético-político. El trabajo busca provocar y provoca. Está destinado a una dura crítica e invalidación por quienes buscan preservar las formas "clásicas" de organización social y concentración de poder. Al mismo tiempo, está destinado a propiciar cuestionamientos, a mover pensamientos y afectos sobre las actuales condiciones de vida y trabajo para quienes practican la música y para quienes la aprecian. La problematización que nos propone es un primer e importante paso porque abre la puerta a la toma de conciencia no solo de la situación de la música

$1 \quad$ Puertorriqueña. Doctora en Filosofía con especialidad en Psicología. Catedrática jubilada, Departamento de Psicología, Facultad de Ciencias Sociales de la Universidad de Puerto Rico. Correo electrónico: wandacr@gmail.com 
clásica en Costa Rica sino de otras formas de expresión artística más allá de límites nacionales.

El texto que nos ofrece José Manuel Rojas González aborda la problematización del discurso eurocéntrico, excluyente y repetitivo que ha utilizado la música "clásica" como instrumento de colonización. Rojas presenta un espléndido ejercicio en reflexividad histórica, una práctica desafortunadamente ausente en muchas disciplinas y muy valorada en la aproximación históricocultural a la explicación del origen y desarrollo de la mente humana. La reflexividad histórica se ocupa del escrutinio de los discursos producidos en el pasado con la doble finalidad de entender sus vínculos con los contextos de su producción y de usar ese entendimiento para una mejor comprensión de las acciones epistémicas actuales. Las prácticas epistémicas que le interesan a Rojas son las que se ocupan de producir y comunicar conocimiento sobre la música y demuestra una gran maestría en el análisis de estas, desde la selección de piezas musicales para los conciertos hasta los énfasis en los aspectos técnicos en la ejecución musical. En un minucioso análisis de esas prácticas que cubre de 1971 a 2011, Rojas marca eventos significativos en los registros oficiales de la música clásica en Costa Rica, así como eventos cuya significación ha permanecido en los márgenes, fuera del escrutinio público por 30 años. El peritaje que demuestra Rojas en estas temáticas, fundamentado en documentación empírica y una historia personal de vivencias relacionadas con la música, no debe despistarnos, pues la reflexión que realiza trasciende los abordajes tradicionales de la historiografía.

El análisis que el autor realiza pone de manifiesto la relación entre los discursos oficiales y las prácticas sociales atravesadas por diversos tipos de ideologías, principalmente sociopolíticas y religiosas. Su argumento es que esas prácticas que se justifican a partir de unos entendidos de gran cultura encubren formas de colonización en las que se configuran mentalidades, subjetividades e identidades. Elabora este argumento en un cuidadoso ejercicio de deconstrucción de cinco grandes mitos. Estos son: 1) la sentencia "¿Para qué tractores sin violines?" enunciada por José Figueres Ferrer en 1970, 2) el Teatro Nacional como espacio único de la "cultura", 3) el piano como instrumento dominante en la educación musical, 4) la figura dominante del Director de Orquesta, y 5) y el repertorio repetitivo y sesgado de la Orquesta Sinfónica Nacional. Para Rojas, la sentencia, que provocativamente subvierte en el título del libro, impulsó un proyecto de hegemonía cultural bajo la retórica de equiparar el desarrollo económico-material con el espiritual. En el proceso fueron marginalizadas o relegadas formas musicales que no se ajustaban a lo clásico, lo que tuvo un impacto en el desarrollo de formas musicales alternativas. El análisis de la significación del Teatro Nacional que realiza Rojas es también una demostración de lo que se encubre bajo la apariencia. Reta la significación dominante en la vida pública costarricense de este teatro como patrimonio nacional, como propiedad colectiva. En su apreciación de la arquitectura del 
teatro y su ubicación en la geografía de la ciudad y lo que ocurre en su interior y en sus observaciones sobre los sujetos que deambulan y realizan actividades de sobrevivencia en sus alrededores, encontramos una aguda crítica social. Lo mismo ocurre con su argumentación en torno a la significación del piano como instrumento dominante en la música clásica en Costa Rica y como instrumento de dominación en procesos de colonización y de demarcación de clases desde que dichos procesos se iniciaron en América Latina. El tema del poder y su manejo atraviesa el análisis del cuarto y quinto mitos. La función del Director de la Orquesta es analizada en clave foucaultiana, al destacar los actos de dirigir y vigilar. Pero, el poder del Director se revela también en su rol en la selección de obras para los repertorios que, según el análisis histórico que realiza por el autor de estos, revelan una tendencia a la repetición.

En la elaboración de sus análisis y argumentos para la deconstrucción de los mitos, Rojas nos regala una lección magistral en transdisciplinariedad, comprendida como la organización de saberes que traspasa radicalmente los límites tradicionales de las disciplinas. Al referirse a esta, Edgar Morin la define como una forma de organización de saberes que trasciende los límites tradicionales de las disciplina de una forma radical. Esto puede entenderse como enfocar en el análisis entre disciplinas, en lo que las atraviesa a todas o en lo que está más allá de ellas. En cualquier caso, se trata de entender y explicar los fenómenos como unidades complejas, imposibles de comprender si se fragmentan en elementos aislados, como lo ha hecho la ciencia tradicional. El texto de Rojas articula un discurso en el que se funden las fronteras de la arqueología del conocimiento, la antropología cultural, la sociología, la psicología y, por supuesto, la musicología (particularmente la historiografía de la música). En este sentido, es un ejemplo a emular por la variedad de niveles de análisis empleados para abordar el complejo tema de las formas de producción, distribución y uso de la música "clásica" en Costa Rica. Alcanza esos niveles de análisis por la síntesis que logra de producciones epistémicas diversas como la Teoría Crítica, el Deconstruccionismo, la Arqueología del conocimiento/poder, la Semiología, los Estudios Coloniales, entre otras.

Rojas logra su objetivo de una mirada crítica a la historia de la música clásica en Costa Rica, pero el resultado de su deconstrucción apunta a una reconstrucción posible que, por supuesto, no es un proyecto individual. Esa reconstrucción debe asentarse, para empezar, en una transformación de las prácticas educativas en formación musical que no implica negación o renuncia a formas del pasado sino un posicionamiento crítico ante ello. Se trata de una transformación que reconozca la música como psicotecnia del sentimiento y del intelecto, como herramienta para construir pensamientos y afectos, para formar conciencias, subjetividades e identidades. Para Rojas, la educación que puede propiciar estos desarrollos debe asentarse en lo que, siguiendo a Boaventura de Sousa Santos, llama ecologías de las temporalidades. Estas ecologías en las que sujeto y ambiente conforman una unidad indivisible se 
oponen a la idea de culturas hegemónicas o monoculturas. La articulación de estas ecologías con prácticas educativas fundamentadas en una pedagogía crítica que ofrece perspectivas de transformación para la historia de la música en Costa Rica. Pero, en realidad, el libro trasciende el límite territorial porque hay razones para pensar que los mitos que deconstruyó existen con igual o variada forma en otros contextos. Hay, sin duda, terreno fértil para la investigación de la historia musical desde perspectivas críticas a nivel internacional.

\section{Referencias}

Morin, Edgar. (s.f.) ¿Qué es la trasdisciplinariedad? Recuperado de http://www. edgarmorin.org/que-es-transdisciplinariedad.html

Rojas González, José Manuel. (2015). ¿Para qué carretas sin marimbas? Hacia una historia crítica de la práctica de la música "clásica" en Costa Rica (1971-2011). San José: Editorial Arlekín.

Sousa (de) Santos, B. (2012). De las dualidades a las ecologías (2012). La Paz: Red Boliviana de Mujeres Transformadoras de la Economía. Recuperado de http://www.boaventuradesousasantos.pt/media/cuaderno\%2018.pdf 